\title{
INTERVENÇÃO PSICOPEDAGÓGICA NO ENSINO SUPERIOR
}

\author{
Caio Cesar Gomes ${ }^{1}$ \\ Universidade Federal de Santa Maria-UFSM \\ Silvia Maria de Oliveira Pavão \\ Universidade Federal de Santa Maria-UFSM
}

\section{RESUMO}

Este artigo teve por objetivo descrever como ocorre o acompanhamento psicopedagógico no Ensino Superior. O método qualitativo, com uso do estudo de caso, como forma de elucidar os processos envolvidos, mostram a prática psicopedagógica. Os resultados e discussão, descrevem as etapas que caracterizam o acompanhamento psicopedagógico, os processos envolvidos na avaliação, nas relações estabelecidas entre o sujeito e o profissional da área psicopedagógica e a utilização de algumas práticas. Conclui-se salientando que a psicopedagogia nesse nível de ensino, tem a prática da escuta dialogal e o estabelecimento de um vínculo terapêutico a partir de metas, como intervenções potenciais para o alcance dos objetivos acadêmicos.

PALAVRAS-CHAVE: Ensino Superior. Aprendizagem. Acompanhamento Psicopedagógico.

\footnotetext{
${ }^{1}$ Psicólogo. Formado pela Universidade Católica de Pelotas. Especialista em Psicoterapia Clínica. Possui larga experiência em avaliação e clínica psicopedagógica, assim como psicoterapias em crianças, adolescentes e jovens adultos. Mestre em Saúde e Comportamento UCPEL (Universidade Católica de Pelotas). Doutor em Ciências Sociais: Políticas e Práticas Públicas pela UNISINOS (Universidade do Rio dos Sinos). Psicólogo Clínico. Santa Maria-RS.

Endereço para Correspondência: Rua Portugal, 199. Bairro São João. Santa Maria RS. CEP 97030490. Telefone: (55) 991311192

2 Educadora Especial, formada pela Universidade Federal de Santa Maria. Experiência em clínica psicopedagógica, na avaliação e intervenção de crianças, adolescentes e jovens adultos universitários. Doutora em Educação pela Universidade Autônoma de Barcelona (UAB-ES). Pós-doutorado em Educação. Universidade Federal de Rio Grande do Sul. (UFRGS). Professora do Departamento de Fundamentos da Educação e dos Programas de Pós-Graduação e Educação-PPGE e de Pós-Graduação em Políticas Públicas e Gestão da Universidade Federal de Santa Maria. UFSM. RS.

Endereço para Correspondência: Rua Portugal, 199. Bairro São João. Santa Maria RS. CEP 97030490. Telefone: (55) 999786675
} 


\section{INTERVENTION PSYCHOEDUCATIONAL IN HIGHER EDUCATION}

\section{ABSTRACT}

This article aimed to describe how psychopedagogical monitoring occurs in Higher Education. The qualitative method, using the case study, as a way of elucidating the processes involved, shows the psychopedagogical practice. The results and discussion describe the steps that characterize the psychopedagogical follow-up, the processes involved in the assessment, the relationships established between the subject and the professional in the psychopedagogical area and the use of some practices. It concludes by emphasizing that Psychopedagogy at this level of education, has the practice of listening to dialog and the establishment of a therapeutic bond based on goals, as potential interventions to achieve academic goals.

Keywords: college education, learning, psychopedagogical assistance.

\section{Introdução}

A psicopedagogia é definida como área de conhecimento e estudo da aprendizagem humana, que se aplica as suas potencialidades e dificuldades. Para Noffs; Rodrigues, a psicopedagogia é o estudo do processo de aprender, evoluções e fatores afetos as "alterações na aprendizagem, como reconhecê-las, tratá-las e preveni-las" (2011, p. 285). A intervenção psicopedagógica decorre da ação do psicopedagogo, que aliado aos procedimentos e recursos auxiliares a sua prática orientada por uma abordagem transdisciplinar focaliza a superação ou minimização das dificuldades de aprendizagem (WEISS, 2001; CIASCA, 2003; BOSSA, 2007; NOFFS; RODRIGUES, 2011; ROTTA; BRIDI FILHO; BRIDI, 2016).

Aprender consiste no processo que une o ser humano a cultura, garantindo-lhe a sobrevivência. Estudos sobre a aprendizagem humana, conferem a esse processo um teor de essencialidade da vida. $O$ aprender, enquanto sujeito frequentando uma academia, pressupõe que ele já percorreu muitas etapas e supostamente, esta base cognitiva, afetiva e cultural, em muito já esteja constituída. Isso quer dizer, para exemplificar o que se está defendendo como aprendizagem ou suporte para a aprendizagem em nível de Ensino Superior e que não está dissertando sobre a constituição de funções mentais, mas sim de compreensão de conteúdos, tendo como base uma formação subjetiva que, em princípio, deve existir (CATANIA, 1999; CLAXTON, 2005).

Os níveis de aprendizagem empreendidos pelos estudantes da Educação Infantil até o Ensino Superior são muito variáveis, posto que cada nível de ensino, tem um grau de complexidade programática que deve estar relacionado à evolução cognitiva correspondente do estudante. O avanço dos níveis escolares percorre, progressivamente, do simples para o complexo, e assim os conteúdos de ensino desafiam a prontidão do estudante, evidenciados pelo amadurecimento das funções psicológicas, cognitivas e afetivas, prioritariamente, durante todo o processo educacional. É quando a aprendizagem encontra algum obstáculo, que a intervenção psicopedagógica, em qualquer um desses níveis, é recomendada.

É mais facilmente aceita a ideia, que as dificuldades de aprendizagem, ocorrem nos anos iniciais do processo de escolarização formal (aproximadamente 6 ou 7 anos de idade), quando os sujeitos, recém ingressos no âmbito das aprendizagens formais - a escola - iniciam o desenvolvimento e o amadurecimento das suas funções mentais em processos de adaptação, aceitação 
de normas, regras e formas diferenciadas de manifestar sua ação e interação no mundo. Tal interpretação pode ter diferentes repercussões, uma vez que as crianças frequentam cada vez mais cedo as instituições de educação, seja nos cuidados básicos iniciais, os berçários e creches, até os anos iniciais do Ensino Fundamental (por volta dos 11 ou 12 anos de idade).

Decorre disso, que a institucionalização da infância seja uma realidade - porque os pais e cuidadores precisam trabalhar, passando grande parte do seu tempo fora de casa, integrando o sistema produtivo - implicando no processo de aprendizagem, diferenciais que podem promover demandas que dificultem a aprendizagem. Tais dificuldades podem acompanhar perdurar durante a vida jovem e adulta, ou seja, podem persistir durante o desempenho universitário. Estudantes do Ensino Superior, em princípio, possuem maior clareza sobre as suas próprias condições de aprendizagem e, não raro, eles mesmos procuram recursos para vencer os desafios acadêmicos. Entretanto, parece não ser uma prática comum, pois, o mundo universitário, recebe o estudante em condições de aprender. Era o que se acreditava e por isso, havia a crença de que o público universitário deveria ter condições para aprender naturalmente ou serem autodidatas, pois são pessoas, que, em tese não precisam de qualquer tipo de ajuda, para instruir-se.

Com o advento das Políticas Nacionais Inclusivas, e da democratização do acesso ao Ensino Superior (BRASIL, 1990, 2004, 2008, 2014, 2015, 2016), essa realidade vem sendo modificada. As universidades acolhem um expressivo número de estudantes, com diversificados níveis de preparação para a aprendizagem acadêmica.

Desse modo, se questiona acerca das reais condições de aprendizagem desses sujeitos, que uma vez tendo ingresso garantido na Educação Superior, seriam também as práticas pedagógicas desenvolvidas nas universidades flexibilizadas para todos os estudantes?

Diante disso, esse estudo se reporta as propostas de intervenção psicopedagógica, tendo como objetivo descrever como ocorre o acompanhamento psicopedagógico no Ensino Superior.

A relevância social e científica do estudo, considera que os desafios desta natureza têm se apresentado, pois práticas tradicionais de ensino, não têm garantido o sucesso na aprendizagem e a conclusão do curso superior almejado, e o número de estudantes que concluem o curso superior é aquém dos que ingressam, deflagrando que o índice de evasão, repetência e retenção é expressivo (BRASIL, 2016). Tais prerrogativas, sugerem que os estudantes, em algum momento da sua vida acadêmica, possam ter necessitado de apoio psicopedagógico para superar impeditivos à conclusão do curso superior. O apoio psicopedagógico mostra-se como uma das possibilidades que pode amenizar a evasão, a repetência e a retenção. $O$ texto se estrutura, a partir dessa introdução, com mais quatro partes, a metodologia, a descrição do processo pedagógico, o relato do caso e as considerações finais.

\section{Metodologia}

Pesquisa do tipo qualitativa quanto a abordagem, coleta e análise dos dados (MINAYO, 2011; PRODANOV; FREITAS, 2013). A coleta de dados se caracterizou pela explanação de um estudo de um caso clínico, cujo desenvolvimento e intervenção ocorreu em uma Instituição de Ensino Superior, localizada na região sul do Brasil. Na referida Instituição, em um espaço destinado a atenção aos estudantes, o psicopedagogo pode atuar individualmente ou em uma equipe multiprofissional, mas com funcionalidade interdisciplinar, considerando que muitas vezes o estudante precisa ser acompanhado por mais de um profissional: fonoaudiólogo, fisioterapeuta, psicólogo, psiquiatra, educador especial, dentre outros. 
O controle do desempenho acadêmico do estudante é utilizado, tanto para fundamentar a estruturação do acompanhamento, como para monitorar a progressão em relação às necessidades de aprendizagem, que motivaram a procura de ajuda. As etapas previstas para o acompanhamento psicopedagógico que compõem a sequência do acolhimento são abordadas para o estudante com a finalidade de esclarecê-lo e de envolvê-lo com a sua terapêutica acadêmica.

O processo todo é planejado para que a sua realização ocorra em um tempo determinado: geralmente é prescrito para ocorrer durante um semestre letivo. $\mathrm{O}$ acompanhamento abrange circunstâncias outras que vão além da relação do sujeito com o psicopedagogo ao considerar todas as demais circunstâncias envolvidas no desempenho acadêmico. Para Daltro; Ponde (2011, p. 108), na educação superior, o ambiente de aprendizagem "se constitui como uma experiência de amadurecimento. Oferece ao jovem a possibilidade de problematizar as suas verdades e consequentemente identificar a complexidade existente no mundo dos adultos". Por isso a ação psicopedagógica, nesse nível de ensino deve priorizar as construções cognitivas e psicológicas obtidas pelo estudante, respeita e incentiva as formas como ele constrói o seu conhecimento (PAVÃO; CEZAR, 2015; PAVÃO; SOUZA, 2018). Envolve diferentes formas de abordagens com os familiares deste sujeito, pois é com eles que se pode aprender de que maneira o estudante foi ensinado a aprender e por meio deste conhecimento utilizar metodologias capazes de incentivar a ressignificação da sistemática da aprendizagem (GASPARIAN, 2012).

A explanação do estudo de caso clínico, evidencia de que forma a dificuldade de compreensão dos conteúdos das disciplinas implica na aprendizagem e no rendimento acadêmico, em praticamente todas as disciplinas do curso. Cabe salientar a importância, de considerar a prática psicopedagógica na Educação Superior, como uma realidade, mesmo que, a procura pelos estudantes e professores, ainda seja restrita a um quantitativo pouco expressivo. Acredita-se que esta realidade se dê pela pouca oferta pelas Instituições de Ensino Superior do serviço na área da psicopedagogia, embora, seja uma prática prevista no Plano Nacional de Educação (BRASIL, 2015).

\section{Processo e Acompanhamento Psicopedagógico}

Quando se aborda sobre atividades psicopedagógicas, há uma tendência ao entendimento de que é uma prática educacional aplicada ao Ensino Básico, correspondente aos anos iniciais do processo de escolarização formal (sete a 14 anos de idade). A impressão que perdura, enquanto educadores é a de que são as crianças e os jovens com idade entre sete e 14 anos, ou pré-adolescentes os únicos a apresentarem alguma necessidade de ajuda durante a evolução escolar. A escolarização, embora com nomenclaturas diferenciadas, conforme os níveis progridem, não deixa de ser composta por uma continuidade de desafios, organizados a partir do mais simples, rumando aos conteúdos mais complexos. Da mesma forma acontece com o estudante que participa da jornada acadêmica de nível superior, ou seja, ele está preparado para lidar com os conteúdos mais simples e básicos do curso. São conteúdos adequados à prontidão, que qualifica a população que frequenta tais níveis e respectivamente os currículos que os compõem.

Conforme vão prosseguindo e avançando para os níveis mais elevados, geralmente distribuídos em semestres, adquirem conhecimentos - novos conceitos e valores -, desenvolvem habilidades e preparam-se para lidar com a complexidade progressiva do conhecimento. Continua a maturação biológica, com repercussão psicológica, embora, não tão intensa como caracterizado nas fases iniciais da aprendizagem, fatores que corroboram para a ampliação do conjunto de conceitos, que favorecem a representação significativa do conhecimento. Cada nível escolar, portanto, contém graus específicos de complexidades que vão ampliando conforme ocorre a evolução acadêmica. 
Esta progressão considera certos graus e tipos de empenhos cognitivos, afetivos e físicos, que serão instigados, desenvolvidos e discernidos conforme se apresentam as proposições para avançar em complexidade. Estabelecendo uma relação de competência entre os progressivos desafios escolares e a prontidão do estudante para corresponder a eles. A relação entre os desafios e as condições internas do estudante irá gerar condições de avanço acadêmico ou de resistências em direção ao conhecimento. Comparável à regulação explicada por Piaget (2009), ao se referir aos processos da assimilação, a acomodação e o correspondente desequilíbrio. Um ciclo contínuo e interminável existente no processo evolutivo da aprendizagem e de assimilação e compreensão da realidade externa, ou seja, para a efetivação da representação.

Um estudante ao transcorrer pelos progressivos níveis educacionais, não o faz assimilando os conteúdos disponibilizados pelas disciplinas, sem fazer relação com os conhecimentos anteriores e, nem o faz, sem aproveitando de atributos cognitivos utilizados na aprendizagem em etapas anteriores, considerando que o surgimento dos mais complexos estejam apoiados nos anteriores. A complexização da funcionalidade cognitiva é favorecida pela complexidade progressiva dos conteúdos acadêmicos propostos. Embora haja esta relação, o amadurecimento cognitivo não está atrelado à complexidade dos conteúdos, no entanto, é necessário que o primeiro esteja presente para que possa assimilar o segundo (PIAGET, 2009).

Os atuais desafios educacionais do Ensino Superior têm apresentado situações inéditas e surpreendentes, tanto para o sujeito quanto para os profissionais envolvidos, carecendo de metodologias adequadas em suas práticas pedagógicas. Dessa forma, um suporte, uma ensinagem, uma preparação para lidar com este contexto se faz necessária. Uma ensinagem capaz de favorecer para que o estudante desenvolva estilos de aprendizagem correspondentes ao nível acadêmico universitário (FERNANDEZ, 2001; BRASIL, 2012).

Aprender utilizando somente o potencial de cada um, quase de forma natural ou num processo empírico de ensaio e erro, sem amparo científico, é a metodologia que, convencionalmente, se tem considerado suficiente, para que o estudante percorra os níveis educacionais existentes. E não deixa de ser dessa forma que ainda acontece, no entanto, nem todos os sujeitos conseguem extrair o melhor das potencialidades que já possuem, apenas amadurecendo e correspondendo aos progressivos desafios escolares, no contexto atual. Por diversos fatores isso acontece dessa forma. Alguns se desenvolvem em lares que facilitam o uso de metodologias para aprender, outros se desenvolvem em condições em que nem lares existem. Embora saibamos que tais fatores não sejam significativos em alguns casos; em muitos, determinam derradeiramente a progressão educacional.

A psicopedagogia, enquanto área de conhecimento, busca responder a essas questões, atuando na prevenção, na análise clínica da aprendizagem e na assessoria aos professores quanto as dificuldades metodológicas na prática pedagógica. Para Bossa (2007) consiste em uma área interdisciplinar, pois integra as ciências pedagógicas, psicológicas, neuropsicológicas e psicolinguísticas. Esses profissionais, muitas vezes trabalham em equipe multiprofissional com funcionalidade interdisciplinar, realizando estudos, orientações investigando sobre a melhor forma para lidar com os casos acompanhados.

O acompanhamento psicopedagógico em nível educacional superior está sendo proposto como uma modalidade para suprir as demandas educacionais para os sujeitos que não estejam acompanhando os desafios acadêmicos. O psicopedagogo é um profissional com atribuições específicas e a interação com outros profissionais durante o desempenho das suas atividades é uma das suas características essencial de atuação. Sua prática requer a compreensão global do sujeito que lhe solicita ajuda. Ao lidar com diferentes formas de aprendizagens, uma abordagem isolada o impediria da construção de um plano de ação abrangente. Conhecer a modalidade utilizada pelo sujeito para construir o conhecimento e ou as dificuldades que ele 
possa apresentar para realizar tal construção embora sejam conhecimentos iniciais básicos para as posteriores ações em favor da aprendizagem é mais bem construída quando realizadas em ações interdisciplinares.

É necessário que a investigação psicopedagógica, área de atuação interdisciplinar (BOSSA, 2007), seja complementada pela averiguação de áreas afins, por exemplo, a Fonoaudiologia, a Psicologia, a Educação Especial, além de profissionais de outras áreas como a médica e suas especialidades, a do serviço social e outras mais que poderão emergir conforme a idiossincrasia de cada caso.

A compreensão interdisciplinar das qualidades de aprendizagem do sujeito em acompanhamento complementará os indicativos educacionais obtidos pelo desempenho acadêmico tornando-se importante tanto para o diagnóstico psicopedagógico, como para a construção do plano das abordagens, das tarefas-metas. As tarefas-metas são ações que o estudante deverá realizar, no intervalo de tempo, entre um acompanhamento e outro. São estruturadas conforme as áreas específicas avaliadas, que envolve as capacidades para aprendizagem o nível de aprendizagem obtido pelo sujeito e ao grau de complexidade presente em suas atividades acadêmicas.

Cabe lembrar que se está referindo a avaliação do estudante de nível superior, portanto, inclui o estudo de desempenho e modelos de aprendizagem desenvolvidos em uma longa jornada percorrida dentro do sistema educacional, na qual foram vivenciados desafios de níveis elevados em qualidade e quantidade de conteúdos, ambos marcados por complexidades crescentes.

A compreensão da performance acadêmica integral é indispensável para delinear as ações do psicopedagogo. Tendo as suas prescrições psicopedagógias balizadas pelo desempenho acadêmico e pelo motivo pelo qual o sujeito procura ajuda, poderá definir a composição da prática clínica pedagógica a ser definida e almejada. O entendimento da performance do estudante favorecerá, também, para esclarecer se há outras implicações juntamente com as que estariam associadas ao motivo que o trouxe ao acompanhamento. Por exemplo: psicológicas, sociais, culturais, de identidade, enfim uma enormidade de outras possibilidades pode fazer parte do desempenho acadêmico. Todas as informações possíveis sobre o desempenho acadêmico facilitam o entendimento da sua modalidade de interação com o conhecimento - quais fatores outros fazem parte da modalidade de aprendizagem - e dessa forma identificam-se as demandas educacionais para o acompanhamento psicopedagógico.

Em uma instituição de Ensino Superior, pressupõe-se que o sujeito possua, até certa medida, circunspeção para avaliar a sua condição de sujeito que aprende. Pressupõem-se, que é a qualidade da complexidade em si dos conteúdos ou dos métodos utilizados pelo estudante para aprender, que poderão empobrecer o seu rendimento acadêmico. No entanto, outras implicações como as condições emocionais e outras mais isoladamente ou associadas, poderão compor um conjunto de fatores que impactem negativamente na aprendizagem.

Possuir os registros sobre o desempenho acadêmico do estudante e relacioná-los com o seu histórico escolar, juntamente com a hipótese sobre como estes podem estar relacionados com o que o motivou a procurar auxílio, ratificando, é condição indispensável para construir o delineamento dos processos e das etapas para acompanhamento psicopedagógico.

O universitário, não raras vezes, pode procurar de maneira voluntária esse serviço. Geralmente ele identifica tal necessidade, no entanto, pode também ser encaminhado por algum professor que a tenha identificada. Há casos em que colegas ou amigos, que já tenham utilizado esse acompanhamento ou que tenham conhecimento sobre ele, façam a sugestão. Nestes casos há melhor 
aceitação e as resistências e desconfianças referentes aos propósitos do acompanhamento psicopedagógico que, por vezes surgem frente a acompanhamentos desta natureza, praticamente inexistem. Outros profissionais, como os supracitados, também, realizam este encaminhamento, embora nestes casos seja mais comum as dificuldades escolares estarem associadas a outras. As etapas que caracterizam o processo psicopedagógico são: a Entrevista inicial, Avaliação de áreas específicas, o acompanhamento (CIASCA, 2003; GUINÉ, 2009; GOMES; PAVÃO, 2013).

As averiguações realizadas nesta etapa assemelham-se ao acompanhamento clínico realizado em outras áreas afins, no entanto, sempre focadas na história educacional pregressa. Investiga-se o motivo pelo qual o sujeito recorreu à Psicopedagogia, destacando-se, a principal queixa, dos aspectos gerais que se apresentam associados. A constatação de que o rendimento acadêmico baixo e o encaminhamento realizado por um professor, por exemplo, costumam mesclar-se às causas reais da procura. Por isso é imprescindível compreender se o sujeito possui este discernimento, ou seja, se ele entende a diferença entre a proposta de acompanhamento sugerido e compreensão que possui sobre o seu desempenho acadêmico. Medos familiares, de represálias ou fatos semelhantes, por se tratar de estudantes de terceiro grau, nem sempre são as causas centrais, embora, algumas vezes, componham o discurso de chegada ao acompanhamento. Exceção em casos de comprometimento emocional ou histórico de uso de substâncias psicoativas.

Descrever as percepções sobre o seu rendimento escolar não é fácil para o estudante, mesmo tendo conhecimento sobre elas. Por isso um clima receptivo, objetivo e sem a presença de componentes transferências regressivas ${ }^{1}$ são importantes para facilitar a exposição das argumentações sobre o motivo que o trouxe à Psicopedagogia. Quanto mais espontâneas forem as exposições por parte do estudante, mais facilitará o psicopedagogo compreender sobre a modalidade de aprendizagem utilizada por ele, favorecendo a construção das práticas psicopedagógicas.

No acompanhamento de universitários, devido ao amadurecimento da personalidade, a presença de familiares nem sempre é necessária, no entanto, entrevistas com os familiares sempre agregam esclarecimentos. Geralmente são elucidativas para o conhecimento de como a família se relaciona com o conhecimento acadêmico. Saber o grau de instrução dos pais, dos irmãos, assim como conhecer sobre a origem do estudante: se é urbana ou rural, contribuem para a compreensão da modalidade da interação, que ele estabelece com o conhecimento, sendo indicadores para a elaboração das ações psicopedagógicas.

É mais raro, no nível universitário, mas há pais, que ainda acompanham os filhos "muito de perto", nesta etapa educacional. Uma entrevista com eles, nestes casos, pode contribuir para avaliar também o grau de independência que o filho conseguiu atingir e, assim, diferenciar se a necessidade de acompanhamento psicopedagógico é mesmo para o filho ou se há necessidade de realizar orientações aos pais.

A avaliação de áreas específicas como a escrita, a socialização, a motivação, a compreensão, a atenção, a memória e o estilo cognitivo utilizado na aprendizagem são essenciais para mapear as que devem ser focadas no acompanhamento psicopedagógico (CIASCA, 2003; GUINÉ, 2009).

Para identificar estas áreas podem ser utilizados instrumentos informais e não padronizados, desde que se mostrem adequados para a finalidade. O Psicopedagogo pode construir os próprios instrumentos. Conforme já exposto ele pode recorrer a outros profissionais para obter

Procedimento presente nos processos psicoterapêuticos originários da teoria da psicanalítica e que se refere à projeção dos pacientes de imagens inconscientes e regressivas no psicanalista (FREUD, 2010). Essencial para a interpretação de fatores inconsciente conflitivos, no entanto, não necessários na abordagem psicopedagógica. 
informações complementares e até mesmo para acompanhamento paralelo. Existem, também, instrumentos formais à disposição do psicopedagogo, os quais são excelentes para o levantamento da qualidade das funções mentais e características de personalidade. Utilizados de maneira associada às demais informações contribuem para uma boa avaliação. A flexibilidade no uso destes instrumentos, desde que fidedignos, não afeta o resultado da avaliação, que vem a ser o conhecimento das áreas de conhecimento do sujeito, como ele as construiu e como ele as utiliza.

Conhecer como o sujeito se relaciona com o objeto de seu conhecimento, ou objetos de conhecimento, é um feito necessário, pois é prioritariamente por meio deste conhecimento que o Psicopedagogo poderá construir um plano de ação e estabelecer as tarefas-metas.

A partir da avaliação são estabelecidas as tarefas-metas, que são ações pedagógicas, a serem atingidas, tendo como foco a superação da dificuldade acadêmica, motivo que o estudante recorreu ao acompanhamento psicopedagógico. Ressalta-se que as ações metas são traçadas em conjunto, entre o sujeito da aprendizagem - aprendiz - e o Psicopedagogo, desenvolvidas a partir do conhecimento, por parte do psicopedagogo sobre como o sujeito, utiliza os seus recursos de aprendizagem, durante a construção do seu conhecimento. Geralmente, evidencia-se uma meta ampla, que representa a dificuldade central e que está relacionada ao motivo para o acompanhamento. Esta é o grande alvo, e irá definir as ações derivadas e que serão descritas em tarefas-metas. Estas derivam do objetivo - dificuldade de aprendizagem - como são constituídas pela meta ampla. Por isso, ressalta-se novamente, a importância de identificar bem o motivo que trouxe o estudante para o acompanhamento e a interpretação que ele possui sobre o seu processo de aprendizagem.

Definidas as tarefas-metas elas são prescritas, uma a uma, para que o sujeito a cumpra a partir de cada acompanhamento. Estas devem ser resolvidas e sucessivamente trazidas em cada acompanhamento para serem analisadas, e posteriormente uma nova tarefa ser prescrita. Elas são compostas pelo conteúdo das disciplinas, as metodologias de aprendizagem e pedagógicas, pelos requisitos e pré-requisitos para a aquisição do conhecimento proposto em sala de aula ou de pesquisa. Em nível psicológico, estas tarefas representam, durante o intervalo entre um acompanhamento e outro, a supervisão que o sujeito leva consigo, e que estará presente em forma de recurso pedagógico, quando ele estiver realizando as tarefas escolares em sala de aula ou fora dela. Em nível cognitivo é a exercitação de capacidade, para a aquisição de conteúdos preliminares e necessários para a compreensão de outros de maior complexidade e em nível moral, valorativo, representa o compromisso assumido com a aprendizagem.

É estabelecido um período determinado para que o acompanhamento seja realizado, e este possui como parâmetro o número de acompanhamentos. Este parâmetro tem se mostrado adequado e foi estabelecido que um encontro por semana durante um semestre letivo é tempo suficiente para o estudante, de maneira geral, aprende a aprender. Em média corresponde a quinze acompanhamentos. Este período tem se mostrado suficiente para que ele desenvolva metodologias de estudos mais eficazes e para que reconheça suas potencialidades cognitivas. O aproveitamento da terapêutica psicopedagógica pode ser acompanhado pelo rendimento acadêmico. Pela motivação do sujeito para a aprendizagem e pela autoestima elevada. A utilização de métodos de aprendizagem mais eficazes altera a forma como ele se relaciona com o(s) objeto(s) de estudo(s).

Relações de informações com outros profissionais existentes na Instituição tem se mostrado eficaz e a formação de uma rede, focada na aprendizagem contribui para um acompanhamento de melhor qualidade. Para que esta rede seja efetivada deve ser realizado um trabalho de esclarecimento, entre os profissionais, sobre o que vem a ser esse acompanhamento. Cada profissional envolvido deve receber orientações sobre os objetivos, procedimentos, durabilidade temporal, 
e deve receber informações sobre as informações úteis para o psicopedagogo. O encaminhamento para profissionais de instituição externas daquela em que o estudante frequenta seu curso, também são recomendados, quando há necessidade da contribuição de uma área profissional que a organização não possui. Neste caso, devem ser repassadas as mesmas orientações para o profissional, embora, o grau de comprometimento possa não ser o mesmo dos que compõem a rede institucional.

A autonomia, por se tratar, quase sempre de estudantes maiores de idade, está sempre presente para escolher continuar ou interromper o acompanhamento, no entanto, enquanto em acompanhamento psicopedagógico é indispensável que o estudante realize as indicações, ou seja, as tarefas-metas e o cumprimento delas no tempo previsto. Obviamente que o planejamento pode ser alterado, adaptando-se as maleabilidades do rendimento do estudante, neste caso, por meio de uma nova construção conjunta entre os sujeitos envolvidos: o estudante e o psicopedagogo.

\section{Estudo de caso}

Para ilustrar a prática psicopedagógica, se explana o acompanhamento de um caso. O contexto do caso é de um estudante com 22 anos, cuja avaliação psicopedagógica inicial constatou acentuada dificuldade de compreensão dos conteúdos das disciplinas, afetando de modo global sua aprendizagem, com repercussão no rendimento de praticamente todas as disciplinas do curso da área das ciências humanas que frequentara. O histórico escolar estava marcado por reprovações por infrequência e pelo rendimento acadêmico comprometido, com notável repercussão na socialização, em especial na sua relação com os colegas de curso, pois, com as sucessivas reprovações, o estudante distanciou-se da sua turma de referência do ingresso na instituição.

Realizava disciplinas mescladas com colegas de diferentes semestres do curso. Perdera a identidade de turma e os laços afetivos com os colegas se tornaram transitórios e instáveis, pois a cada semestre muitos eram substituídos por novos colegas. A transitoriedade vincular dificultava sua participação nos trabalhos em grupo. Os colegas pouco o conheciam ou o identificavam como aquele que não possuía bom rendimento acadêmico. Tornara-se solitário, sem ter para quem recorrer em situações de alguma dúvida sobre os conteúdos das disciplinas, ou ajuda para a realização de trabalhos. Ele próprio se considerava como um estranho, ou excluído. Entendia que também era essa a percepção dos professores.

Os constantes fracassos acadêmicos o colocavam em uma situação de indesejado, pelos colegas, para a realização dos trabalhos acadêmicos. A maioria dos colegas o conheciam por suas dificuldades acadêmicas o que gerou uma imagem de pessoa indesejada. Entretanto, tudo ocorria de forma tácita, o que era muito pior para os seus sentimentos e reforçava nele a noção de exclusão.

Com a legislação educacional vigente (BRASIL, 1996; 2008; 2011) que preconiza a inclusão de alunos e apoio pedagógico para que possam avançar na aprendizagem, esse aluno, em processo de conclusão de curso e precisando elaborar um trabalho acadêmico, cujo objetivo é a escrita de uma monografia ou o trabalho de conclusão de curso, foi encaminhado pela coordenação do curso, para o acompanhamento psicopedagógico.

Ao chegar ao acompanhamento, questionado sobre o motivo do encaminhamento, ele descreve sua dificuldade como "estritamente vinculada à escrita de trabalhos acadêmicos". Mostrava-se queixoso e sentia-se perseguido pelos professores, entendendo que, de certa forma, a culpa também era deles, pois na sua interpretação eles não o ajudavam. 
O procedimento psicopedagógico inicial consistiu na entrevista do tipo anamnese, em que se busca conhecer a história do sujeito. Momento em que foram recolhidos dados relativos ao seu desenvolvimento pessoal, sobre a sua dinâmica familiar e detalhadamente sobre a sua trajetória escolar. Após, e, nesse caso, por tratar de dificuldades na escrita, foi solicitado para que trouxesse os materiais desenvolvidos em aula, trabalhos e provas realizados. Estes proporcionam informações sobre como se constrói a relação com o objeto de estudo e quais são suas áreas cognitivas específicas mais utilizadas na aprendizagem. A partir dessas informações suas dificuldades são identificadas. As suas dificuldades estão vinculadas com a ortografia, com a construção gramatical, com o conhecimento específico do tema das disciplinas ou com aspectos motivacionais? Quais destas áreas estariam afetadas e quais estariam comprometendo a sua capacidade de realização das tarefas pedagógicas desenvolvidas nas disciplinas do curso?

As informações obtidas são utilizadas, também, para identificar as áreas onde se concentra as potencialidades do estudante. A identificação destas é para que possam ser mais bem aproveitadas e assim servirem como suportes psicológicos motivadores, para que afetadas possam ser superadas.

A partir desses dados, foi traçado seu perfil educacional e um plano de acompanhamento psicopedagógico, visando atingir o objetivo principal, ou seja, o motivo que o levou a procurar por esse acompanhamento. Assim, ao longo de 14 encontros, foi organizada uma agenda de tarefas-metas para que fossem diariamente desenvolvidas pelo estudante. Estas atividades compreendiam não só as tarefas acadêmicas, como também as extracurriculares, quais sejam: lazer, família, outras responsabilidades.

O aluno apresentava um perfil de raciocínio lento, dispersão acentuada e parecia com pouca consciência sobre as suas dificuldades acadêmicas e pessoais. Isso foi observado a partir da maneira como se expressava em relação ao próprio trabalho acadêmico que realizava. Quando avaliado, por exemplo, na construção de um texto acadêmico, se o professor o considerava com pouca qualidade, este aluno considerava que ele tinha sido muito severo em seus critérios avaliativos. Argumentava ainda que ele, na verdade - palavras do estudante - não correspondia ao solicitado, depreciando, impetuosamente, a capacidade do profissional. Afirmava que quem estava errado, ou quem não tinha competência para avaliá-lo era o professor. No entanto quando ela foi psicopedagogicamente avaliada, por meio de instrumentos informais, ficou constatado, pelos dados colhidos sobre a sua produção acadêmica, que era fato a sua dificuldade de construção textual. Os textos, a fim de esclarecimentos, quando solicitados correspondiam a temáticas desenvolvidas nas disciplinas em curso e os resultados, mesmo assim, não eram adequados. Demonstrava dificuldades para interpretar e para dissertar sobre o que havia escutado em aula. Ao explicar-lhe novamente a tarefa, durante o acompanhamento psicopedagógico e ao solicitar-Ihe para, novamente, responder sobre o que havia entendido, era possível perceber um pouco mais de compreensão.

Não foram observadas dificuldades ortográficas significativas. Esses dados levaram a crer que a dificuldade dissertativa estava relacionada ao pouco conhecimento dos temas tratados e sobre os quais tinha que escrever, seja em trabalhos, provas, ou ainda aulas que tinha que ministrar durante os estágios do Curso. O pouco estudo efetivado pelo aluno comprometia-Ihe significativamente o desempenho. Isso já tinha sido constatado antes mesmo de seu ingresso na universidade, segundo seu próprio relato. Na escola, essas dificuldades tinham sido evidenciadas, mas, não impediram que ele concluísse as etapas existentes nos níveis fundamentais.

Provavelmente, pela receptividade e pela maneira objetiva com que foi tratado desde o início do acompanhamento, ele logo estabeleceu o vínculo terapêutico. De maneira surpreendente, não registrou sequer uma infrequência e, na maioria das vezes, cumpria o solicitado. A partir da agenda de tarefas-metas, construídas em conjunto e com sua concordância, foram-lhe solici- 
tadas as atividades a serem entregues em cada um dos encontros. Caracterizavam-se em parte pelo trabalho dissertativo realizado, com os dados das leituras, explicações relativas ao conteúdo das disciplinas e sobre a metodologia que ele estava utilizando durante os estudos. Também continha, os horários em que permanecia estudando, bem como deveria relatar as demais tarefas que ele tinha se comprometido em realizar.

\section{Considerações finais}

O clima psicopedagógico que predomina no acompanhamento em nível superior é o de escuta dialogal. A escuta dialogal se caracteriza pela conversa franca e aberta, sem julgamentos ou avaliações e fazendo prevalecer as intervenções psicopedagógicas de cunho objetivo e focadas no motivo da busca pelo acompanhamento. O predomínio do diálogo objetivo, sem considerar as possíveis alterações de outros vieses, como as possíveis psicopatologias, que vez ou outra estão associadas as dificuldades acadêmicas, tem como propósito mostrar ao aluno como a realização das tarefas-metas e o desenvolvimento de novas atitudes frente a formação acadêmica, podem gerar melhor eficácia e sucesso na aprendizagem.

Certa cumplicidade entre o psicopedagogo e o sujeito, necessária a construção de novas abordagens e postura frente a aprendizagem está baseada na expectativa do aluno nos resultados decorrentes do apoio e da ajuda recebidos, e por parte do psicopedagogo a confiança recíproca de que é possível alcançar resultados satisfatórios. O fato de trabalhar com o adulto, ou jovem adulto, leva o psicopedagogo a crer na sua capacidade resiliente de aprendizagem, pois muitos dos processos psicológicos que permeiam a aprendizagem são resultados de uma relação de confiança e de metodologia adequada, que geram clima adequado para emersão de potencialidades.

A clareza com que se avalia a modalidade de aprendizagem, historicamente, utilizada pelo sujeito, assim como a clareza com que se identifica as áreas de dificuldade e como elas estão associadas com o motivo que o sujeito chegou ao acompanhamento psicopedagógico são essenciais para o êxito desta prática. Indispensável, também, é a compreensão de que existe um período para que o acompanhamento seja realizado e que as tarefas-metas, definidas conjuntamente entre o sujeito e o psicopedagogo, sejam cumpridas.

No acompanhamento psicopedagógico em nível superior pode-se dizer que existe uma cumplicidade, um comprometimento em busca de melhores resultados acadêmicos, pois são sujeitos que já cruzaram por desafios educacionais com certo êxito, caso contrário, não estariam realizando um curso superior.

O clima de comprometimento, cooperação e de motivação para que as superações sejam alcançadas, são alguns elementos que diferenciam o acompanhamento psicopedagógico de outros níveis de ensino, aquém do nível universitário, pois se dialoga com adultos, em geral, no qual a compreensão do processo educacional é bem nítida. O estudante está se formando em um profissional e definindo a sua vida pessoal, bem diferente da compreensão e da dependência que caracteriza estudantes cursando os níveis escolares anteriores a este. A intervenção psicopedagógica no nível universitário, ainda pode ser considerado um desafio, mas a sua aplicabilidade proporciona bons resultados.

\section{Referências}

BOSSA, Nádia. A psicopedagogia no Brasil: contribuições a partir da prática. 3. ed. Porto Alegre: Artes Médicas, 2007. 
BRASIL. Declaração Mundial sobre Educação para Todos: plano de ação para satisfazer as necessidades básicas de aprendizagem. UNESCO, Jomtiem/Tailândia, 1990.

BRASIL. Ministério da Educação. Lei de Diretrizes e Bases da Educação Nacional, LDB 9.394, de 20 de dezembro de 1996. Disponível em: http://www.planalto.gov.br/ Acesso em: 29 dez. 2018.

BRASIL. Projeto de Lei no 3.582 - 28 mar. 2004. Dispõe sobre a instituição do

Programa Universidade para todos - PROUNI, e dá outras providências. Brasília: MEC, 2004. Disponível em: www.camara.gov.br/sileg/integras/219649.htm Acesso em: 27 nov. 2018.

BRASIL. Política Nacional de Educação Especial na perspectiva da Educação Inclusiva. Brasília: MEC/SEESP, 2008. Disponível em: http://portal.mec.gov.br/seesp/arquivos/pdf/politica.pdf. Acesso em: 29 dez. 2018.

BRASIL. Decreto № 7.611 de nov. de 2011. Dispõe sobre a educação especial, o atendimento educacional especializado e dá outras providências. Brasília: MEC, 2011. Disponível em: < http://www.planalto.gov.br/>. Acesso em: 29 dez. 2018.

BRASIL. Instituto Nacional de Estudos e Pesquisas Educacionais Anísio Teixeira. Plano Nacional de Educação- PNE 2014-2024: Linha de Base. - Brasília, DF: Inep, 2015.

BRASIL. Lei 13.146, de 6 de julho de 2015. Institui a Lei Brasileira de Inclusão da Pessoa com Deficiência (Estatuto da Pessoa com Deficiência). Disponível em: http://www.planalto.gov.br/ ccivil_03/_ato2015-2018/2015/lei/l13146.htm. Acesso em: 4 out. 2019.

BRASIL. Instituto Nacional de Estudos e Pesquisas Educacionais Anísio Teixeira. Censo da Educação Superior 2016 - Notas Estatísticas. Brasília, 2016. Disponível em: https://www.gov.br/inep/ pt-br/areas-de-atuacao/pesquisas-estatisticas-e-indicadores/censo-da-educacao-superior. Acesso em: 4 out.2019.

BRASIL. A consolidação da Inclusão Escolar no Brasil. MEC/SECADI/DPEE: Brasília, DF, 2016a. Disponível em: http://www.ufpb.br/cia/contents/manuais/a-consolidacao-da-inclusaoescolar-no-brasil-2003-a-2016.pdf Acesso em: 05 maio 2018.

CATANIA, A. Charles. Aprendizagem: comportamento, linguagem e cognição. 4.ed. Porto Alegre: Artes Médicas, 1999.

CIASCA, Sylvia Maria (Org.). Distúrbios de aprendizagem: proposta de avaliação interdisciplinar. São Paulo: Casa do psicólogo, 2003.

CLAXTON, Guy. O desafio de aprender ao longo da vida. Porto Alegre: Artmed, 2005.

DALTRO, Mônica Ramos; PONDE, Milena Pereira. Atenção psicopedagógica no ensino superior: uma experiência inovadora na graduação de medicina. Constr. psicopedag., São Paulo, v. 19, n. 18, p. 104-123, 2011. Disponível em: http://pepsic.bvsalud.org/scielo.php?script=sci_ arttext\&pid=S1415-69542011000100010\&lng=pt\&nrm=iso. Acesso em: 16 nov. 2018.

GARCIA, Jesus Nicasio. Manual de dificuldades de aprendizagem: linguagem, leitura, escrita e matemática. Porto Alegre: Artes Médicas,1998. 
GASPARIAN, Maria Cecília Castro. 0 psicopedagogo institucional na construção da solidariedade entre a escola a família e a comunidade. Constr. psicopedag., São Paulo, v. 20, n. 21, p. 66-73, 2012. Disponível em: http://pepsic.bvsalud.org/scielo.php?script=sci_arttext\&pid=S141569542012000200005\&lng=pt\&nrm=iso. Acesso em: 16 nov. 2018.

GOMES, Caio Cesar Piffero; PAVÃO, Silvia Maria de Oliveira. Avaliação psicopedagógica da aprendizagem. São Paulo: Casa do psicólogo, 2013.

GUINÉ, Climent. A avaliação psicopedagógica. In: COLL, Cesar; MARCHESI, Álvaro; PALACIOS, Jesus, et al. Desenvolvimento psicológico e educação. Transtornos de desenvolvimento e necessidades educativas especiais. 2. ed. Porto Alegre. RS: Artmed, 2009.

FERNANDEZ, Alicia. Os idiomas do aprendente: análise das modalidades ensinantes com famílias, escolas e meios de comunicação. Porto Alegre, RS: Artmed, 2001.

FREUD, Sigmund. Obras completas. O mal-estar na civilização, novas conferências introdutórias a psicanálise e outros textos (1930-1936), Rio de Janeiro: Companhia das letras, 2010.

MINAYO, Maria Cecilia de S. Pesquisa social: teoria, método e criatividade. Petrópolis: Vozes, 2011.

NOFFS, Neide de Aquino; RODRIGUES, Carla Maria Rezende. Andragogia na Psicopedagogia: a atuação com adultos. Rev. psicopedag., São Paulo, v. 28, n. 87, 2011. Disponível em: $<$ http://pepsic.bvsalud.org/scielo.php?script=sci_arttext\&pid=S0103-84862011000300009 \&lng=pt\&nrm=iso>. Acesso em: 23 nov. 2018. p. 283-92.

PAVÃO, Sílvia Maria de Oliveira; CEZAR, Amanda do Prado Ferreira. Educação superior: vicissitudes da ação psicopedagógica. Rev. Psicopedagogia. 2015; 32(99): 366-73.

PAVÃO, Sílvia Maria de Oliveira; SOUZA, Carmen Rosane Segatto. Abordagem psicopedagógica do aprender na educação superior. Rev. Psicopedagogia. 2018; 35(106): 51-60.

PIAGET, J. Seis estudos de psicologia. 24. ed. Rio de Janeiro: Forense Universitária, 2009.

PRODANOV, Cleber C.; FREITAS, Ernani C. Metodologia do trabalho científico: métodos e técnicas da pesquisa e do trabalho acadêmico. Novo Hamburgo: Feevale, 2013.

ROTTA, Newra Tellechea; BRIDI FILHO, César Augusto; BRIDI, Fabiane Romano de Souza (Orgs.). Neurologia e aprendizagem: abordagem multidisciplinar. Porto Alegre: Artmed, 2016.

WEISS, Maria Lucia Lemme. Psicopedagogia clínica: uma visão diagnóstica dos problemas de aprendizagem escolar. 6. ed. Rio de Janeiro: DP \& A., 2001.

YIN, R.K. Pesquisa qualitativa do início ao fim. Porto Alegre: Penso, 2016. 